\title{
MECHANICAL BEHAVIOUR OF CHALK RESERVOIRS: NUMERICAL MODELLING OF WATER SENSITIVITY EFFECTS
}

\author{
F. Collin ${ }^{1}$, Y.J. Cui' ${ }^{2}$, Ch. Schroeder ${ }^{1}$ and R. Charlier ${ }^{1}$ \\ 1)Department GeomaC, University of Liège, Belgium \\ 2) CERMES, Ecole Nationale des Ponts et Chaussées, France
}

\begin{abstract}
Chalk is the constituent material of numerous oil reservoirs in North Sea. The mechanical behaviour of a saturated chalk has been largely studied. However, different aspects of its behaviour are not yet well understood: material characteristics depend on the saturating fluids and chalk response is timedependent. This paper proposes the PASACHALK numerical model: an elasto-plastic constitutive law is presented, which reproduces the different plastic mechanisms of the chalk (pore collapse and shear failure) and the influence of pore fluids. The water sensitivity of this soft rock is explained by the existence of suction effects in chalk. Finally, a simulation of a hypothetical reservoir is proposed to show the response of the elasto-plastic model during depletion phase and water injection phase.
\end{abstract}

\section{INTRODUCTION}

Compaction of chalky reservoirs during oil extraction and other important problems like the "casing collapse" or the "chalk production" are related to the mechanical properties of chalk. Controlling compaction is very important because reservoir deformations imply seabed subsidence that endangers the offshore stations.

The most remarkable behaviour of chalk is its water-sensitivity: water injection in the reservoir induces additional subsidence. Though many studies have been already performed on chalks, the basis mechanism of the water sensitivity was not defined. The ongoing EC Research Program Pasachalk aim is to give a better understanding of the chalk behaviour. The origin of the research comes from the comparison between experimental results obtained on Lixhe chalk and on Jossigny silt which showed that the influence of water on pure high porosity chalk is similar to that on partially saturated soils (Delage et al. 1996). Another extensive experimental analysis of the influence of the saturating fluid on Lixhe chalk behaviour concluded that the water-weakening effect might be suction related. Hence the idea appeared to apply the knowledge, the approach, and the tools of the partially saturated soil mechanics to the understanding, description, and modelling of chalk behaviour during changes in saturation fluids, such as when water flooding.

This paper presents the developed constitutive model, which is a cap type plasticity model coupled with the Barcelona one (Alonso et al. 1990) for taking the suction effect into account.

The model parameters are calibrated based on the experimental results. The validation of the model is performed on a water flooding experiment. We show that the model is able to reproduce qualitatively and quantitatively the observed basic phenomena.

Unsaturated flow formulation is necessary here as far as suction has to be known. The flow model used is based on works in relation with the problem of nuclear waste disposal (Collin et al. 2002a). For each fluid (Water and oil), balance equations and state equations are written. In partial saturation conditions, the permeability and the storage law have to be modified: a generalised Darcy's law defines the fluid motion (Bear 1972). Numerous couplings existing between mechanics and flows are considered.

\section{ELASTO-PLASTIC MODEL}

Experiments performed on chalk samples have shown two plastic mechanisms: the pore collapse for high mean stresses (contractant behaviour) and the frictional failure for low mean stresses. The pore collapse could be caused by the breakdown of physico-chemical bonds between the grains inducing some grain-to-grain slip (Monjoie et al. 1990). The frictional failure corresponds to a plastic distortion inducing an increase of porosity.

The two-evidenced plastic mechanisms are modelled by two yield surfaces combined within a cap model: the modified Cam-Clay model is used for pore collapse whereas an internal friction model for friction failure (Collin et al. 2002b). Experimental results show that the chalk strength under extension can be overestimated using an internal friction model, a third yield surface is then adopted to limit traction stresses.

Obviously, the so-defined yield curve is not continuously derivable at the intersections, leading 
to numerical difficulties. However, recent publications provide an elegant way to solve this problem (Simo \& Hughes 1998).

As far as the suction effect is concerned, the model adopts the approach developed in the Barcelona Basic Model (Alonso et al. 1990) where the suction is considered as an independent variable. Suction modifies yield surfaces and produces reversible and irreversible deformations.

The mechanical model is expressed in terms of the following stress invariants and suction:

$I_{\sigma}=\sigma_{i i}$

$I I_{\hat{\sigma}}=\sqrt{\frac{1}{2} \hat{\sigma}_{i j} \hat{\sigma}_{i j}}, \hat{\sigma}_{i j}=\sigma_{i j}-\frac{I_{\sigma}}{3} \delta_{i j}$

$I I I_{\hat{\sigma}}=\frac{1}{3} \hat{\sigma}_{i j} \hat{\sigma}_{j k} \hat{\sigma}_{k i}$

$\beta=-\frac{1}{3} \sin ^{-1}\left(\frac{3 \sqrt{3}}{2} \frac{I I I_{\hat{\sigma}}}{I I_{\hat{\sigma}}{ }^{3}}\right)$

$s=p_{o}-p_{w}$

Where $\beta$ is the Lode angle, $s$ is the suction, $p_{o}$ and $p_{w}$ are the oil and water pressures.

\subsection{General formulation}

The general elasto-plastic relations are formulated in rate form. The strain rate is composed of a mechanical part (superscript $\mathrm{m}$ ) and of suction one (superscript s). Each contribution is partitioned in an elastic (superscript e) and a plastic component (superscript p):

$\dot{\varepsilon}_{i j}=\dot{\varepsilon}_{i j}^{m, e}+\dot{\varepsilon}_{i j}^{s, e}+\dot{\varepsilon}_{i j}^{m, p}+\dot{\varepsilon}_{i j}^{s, p}$

The mechanical elastic part is related to the Jaumann objective stress rate $\tilde{\sigma}_{k l}$ through Hooke's law. For the plastic parts, a general framework of non-associated plasticity is adopted in order to limit dilatancy. In that case, the plastic flow rate is derived from a plastic potential $g_{\alpha}$ :

$\dot{\varepsilon}_{i j}^{m, p}=\dot{\lambda}^{p} \frac{\partial g_{\alpha}}{\partial \sigma_{i j}}$, where $\lambda^{p}$ is a scalar multiplier and $g_{\alpha}$ is the plastic potential related to the plastic mechanism $\alpha$.

Elastic and plastic deformations related to suction changes are defined following expressions given in Barcelona Basic Model. Irreversible deformations are induced when the suction becomes higher than a suction level $s_{0}$.

$\dot{\varepsilon}_{i j}^{s, e}=\frac{\kappa_{s}}{(1+e)} \frac{\dot{s}}{\left(s+p_{a t}\right)} \delta_{i j}=h_{i j}^{e} \dot{s}$

$\dot{\varepsilon}_{i j}^{s, p}=\frac{\lambda_{s}-\kappa_{s}}{(1+e)} \frac{\dot{s}}{\left(s+p_{a t}\right)} \delta_{i j}=h_{i j}^{p} \dot{s}$

Where $e$ is the void ratio, $p_{a t}$ is the atmospheric pressure, $\kappa_{s}$ and $\lambda_{s}$ are elastic and plastic coefficients.

Combining equations (6) to (9), one obtains the following expression:

$\tilde{\sigma}_{k l}=C_{k l i j}^{e}\left(\dot{\varepsilon}_{i j}-h_{i j}^{e} \dot{s}-\dot{\lambda}^{p} \frac{\partial g_{\alpha}}{\partial \sigma_{i j}}-h_{i j}^{p} \dot{s}\right)$

Considering a general hardening/softening plastic law depending on the internal variable $\zeta$, the consistency condition and equation (10) give the expression of multiplier $\lambda^{p}$ and the stress rate can be computed:

$\tilde{\sigma}_{k l}=\left(C_{k l i j}^{e}-C_{k l i j}^{p}\right) \dot{\varepsilon}_{i j}-M_{k l} \dot{s}$

The first term of the right part is the classical expression of an elasto-plastic formulation. The second term is related to the suction.

\subsection{CamClay pore collapse model}

The Modified Cam-Clay yield surface is defined by the following expression:

$f_{1} \equiv I I_{\hat{\sigma}}^{2}+m^{2}\left(I_{\sigma}+\frac{3 c}{\tan \phi_{\mathrm{C}}}\right)\left(I_{\sigma}-3 p_{0}\right)=0$

Where $c$ is the cohesion, $\phi_{C}$ is the friction angle in compression path, $p_{0}$ is the pre-consolidation pressure, which defines the size of the yield surface, and $m$ is a coefficient introduced to take into account the effect of the third stress invariant. 
The plastic flow is supposed to be associated and the internal variable is the pre-consolidation pressure $p_{0}$, which is related to the volumetric plastic deformations $d \varepsilon_{v}^{p}$ following the cinematic equation:

$$
d p_{0}=\frac{1+e}{\lambda-\kappa} p_{0} d \varepsilon_{v}^{p}
$$

where $\lambda$ is the compression coefficient and $\kappa$ is the elastic coefficient.

\subsection{Internal friction model}

A more sophisticated model can be built from the Drucker-Prager's cone by introducing a dependence on the Lode's angle $\beta$, in order to match more closely the Mohr-Coulomb criterion. It consists of a smoothed Mohr-Coulomb plasticity surface. The formulation based on the idea of Van Eekelen (1980) is used. It can be written in a very similar way to the Drucker-Prager's criterion:

$$
f_{2} \equiv I I_{\hat{\sigma}}-m\left(I_{\sigma}+\frac{3 c}{\tan \phi_{\mathrm{C}}}\right)=0
$$

A non-associated plasticity is considered here using a plastic potential definition similar to Eq. 14 where the dilatancy angle $\psi$ is used instead of the frictional angle.

The internal variables of the model are the frictional angles $\phi_{C}$ (for compression paths), $\phi_{E}$ (for extension paths) and the cohesion $c$, which are related to the equivalent plastic strain.

\subsection{Suction effect on yield surface}

Several phenomena are usually evidenced for unsaturated soils:

1. The pre-consolidation pressure $p_{0}$ and the material stiffness increase with suction. This is described by the LC concept of the Barcelona model (Alonso et al, 1990):

$$
p_{0}(s)=p_{c}\left(\frac{p_{0}^{*}}{p_{c}}\right)^{\frac{\lambda(0)-\kappa}{\lambda(s)-\kappa}}
$$

where $p_{0}{ }^{*}$ is the pre-consolidation pressure for null suction, $p_{c}$ is a reference pressure, $\lambda(0)$ is the compression coefficient at zero suction, $\lambda(\mathrm{s})$ is the compression coefficient at suction $s$.

However, chalk experiment does not show an increase of plastic stiffness with suction i.e. water saturated chalk and oil saturated chalk present the same plastic compressibility (Schroeder et al. 2000). Another expression of LC curve has been adopted:

$$
p_{0}(s)=p_{0}(0)+\Delta p_{0} \frac{s}{s+s^{*}}
$$

Where $\Delta p_{0}$ is the pre-consolidation pressure difference between water and oil saturated sample, and $s^{*}$ is a numerical parameter.

2. Cohesion increases with suction, this is modelled using Eq. 17. The influence of suction on friction angle depends on the material studied. Experiment on chalk shows that friction angle is independent of the saturating fluid.

$$
c(\mathrm{~s})=c(0)+k s
$$

where $k$ is a material constant, $c(0)$ is the cohesion at saturated state.

3. Suction changes may create irreversible strains. In the Barcelona model, this is modelled thanks a yield surface, the SI "Suction Increase" curve. When suction becomes higher than a suction level $s_{0}$, plastic strains are created. This yield criterion is introduced in our constitutive law:

$$
f_{4} \equiv s-s_{0}=0
$$

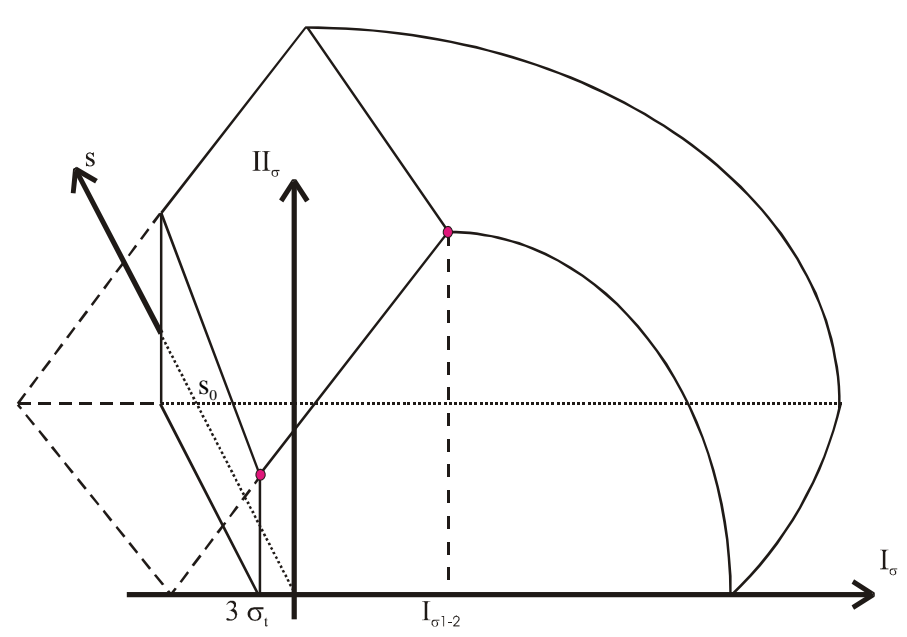

Figure 1. Cap model in the stress space

Figure 1 presents all the yield surfaces in the stress space. 


\subsection{Waterflooding experiment}

The water-flooding test performed on Lixhe chalk initially saturated by SoltrolTM (Schroeder $\&$ al. 1998) allows validation of the developed model.

The sample with an initial porosity $n=40.55 \%$ and permeability $k_{\text {int }}=1 \mathrm{mDarcy}$ has dimensions of $25 \mathrm{~mm}$ of diameter and $50 \mathrm{~mm}$ of height. Four strain gauges are glued on the sample (located respectively from the injection side at a distance of 4, 12, 22 and $30 \mathrm{~mm}$ ), which aims to monitor the evolution of the axial deformation with the waterfront. In addition, an axial LVDT records the global axial deformation.

The initial stress state is isotropic at a level of 18 MPa, just below the expected pore collapse for 'oillike' plug. The injection water pressure is equal to $0.9 \mathrm{MPa}$. Just before the injection front, a small swelling is measured by the strain gauges but a brutal and quasi-instantaneous compaction appears at the waterfront. The final amplitude of the compaction is around $2 \%-3 \%$.

Experiment results of triaxial tests on saturated samples allow us to define the yield surface of oillike and water-like plugs. The transition between these two cases is characterized by results of suction controlled oedometer tests.

The parameters of the mechanical model are presented in Table 1.

Table 1. Parameters of the Cap model

\begin{tabular}{clll}
\hline & Parameter & Value & Unit \\
\hline Elasticity & & \\
& $K_{\text {water }}$ & 612 & $\mathrm{MPa}$ \\
$G_{\text {water }}$ & 500 & $\mathrm{MPa}$ \\
$K_{\text {oil }}$ & 726 & $\mathrm{MPa}$ \\
$G_{\text {oil }}$ & 700 & $\mathrm{MPa}$ \\
\hline Frictional mechanism & & \\
$\phi_{\text {water }}$ & 25 & $\circ$ \\
$\phi_{\text {oil }}$ & 25 & $\circ$ \\
$c_{\text {water }}$ & 1.5 & $\mathrm{MPa}$ \\
$\boldsymbol{c}_{\text {oil }}$ & 2.0 & $\mathrm{MPa}$ \\
$k$ & 0.167 & - \\
\hline CamClay + suction LC & & \\
$p_{0, \text { water }}$ & 10 & $\mathrm{MPa}$ \\
$p_{0, \text { oil }}$ & 22 & $\mathrm{MPa}$ \\
\hline$\lambda$ & & \\
$s^{*}$ & 0.195 & - \\
\hline Hardening rule & 0.2 & $\mathrm{MPa}$ \\
\hline
\end{tabular}

The comparison of the numerical results with the experimental data is shown in Figure 2. The injected water volume evolution is similar. After
$3500 \mathrm{sec}$, the waterfront reaches the top; no more oil is driven out of the sample and water is produced at the top. The computed axial strains at the four gauges present a small swelling followed by a brutal collapse of around 2.5\% (Figure 3 ).

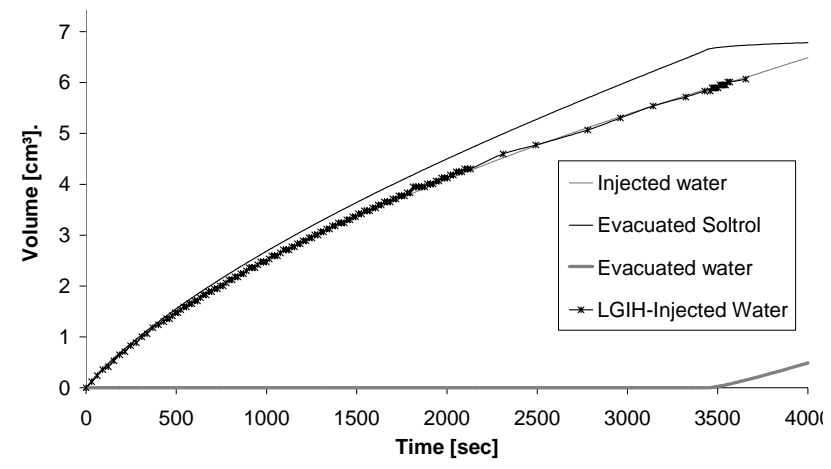

Figure 2. Fluid exchange during water flooding

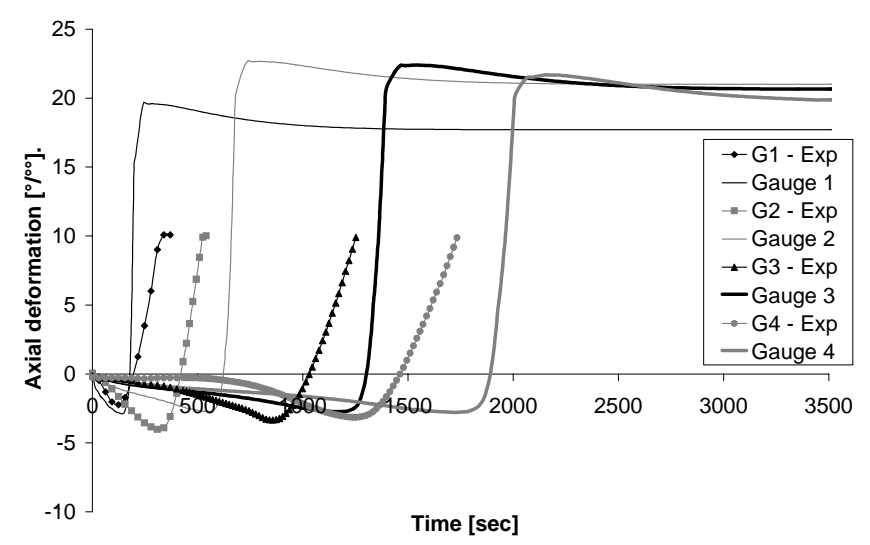

Figure 3. Axial strains at the four gauges

The experiment value of strain stops at $1 \%$, which corresponds to the gauge failure.

The good consistence obtained between the numerical simulation and the experimental responses shows the validity of the developed model for describing the chalk behaviour during water injection.

\section{COUPLED RESERVOIR MODELLING}

The reservoir model used here is similar to the hypothetical one proposed by Homand (2000): it is $2.5 \mathrm{~km}$ long and $300 \mathrm{~m}$ thick. The sideburden and the underburden are assumed to be rigid; a dead load corresponding to the weight of the overburden acts on the upper edge of the reservoir. The initial total stress conditions are those of Ekofisk field i.e. $62 \mathrm{MPa}$ vertical stress and $55 \mathrm{MPa}$ horizontal stress (Teufel et al. 1990). 
All the reservoir edges are supposed to be impervious: the fluids inflows or outflows come only through the wells. In this computations well pressures are controlled in order to reproduce a depletion and an injection phase. The production scheme is the one proposed by Homand (2000) and presented in Figure 4.

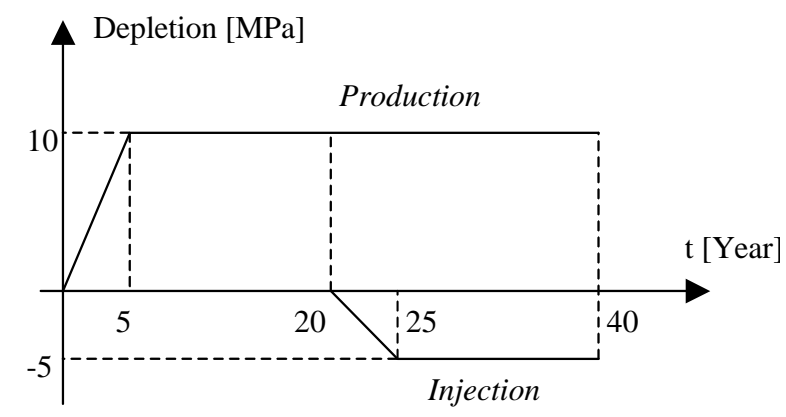

Figure 4. Production scheme

In this model, the injection well is located on the left edge and the distance between the injection and the production well is $2.25 \mathrm{~km}$. The initial pressure condition supposed a uniform suction value of 300 $\mathrm{kPa}$ (neglecting gravity effect on the reservoir thickness) corresponding to an oil pressure of 49 MPa.

The computation is performed using the elastoplastic model and the flow model, with the same parameter used in the water flooding simulation. Except the permeability was modified, related to the scale change between the laboratory sample and the reservoir field.

In the production phase, the oil pressure decrease at well to reach a depletion of $10 \mathrm{MPa}$ after 5 years. Due to hydro-mechanical couplings, this pressure decrease leads to a compaction of the reservoir (increase of the effective stress). Figure 5 shows that compaction is low after 1 year $(40 \mathrm{~cm})$. However, up to 5 years, irreversible deformations appear and compaction reaches a value of 13 meters at the production well after 20 years.

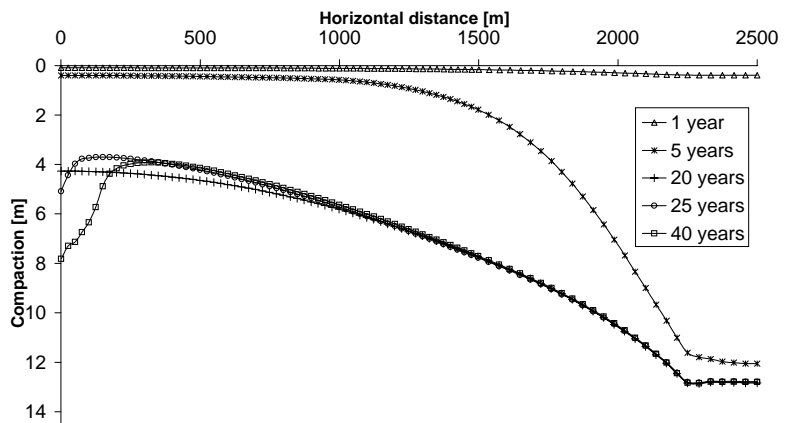

Figure 5. Compaction of the reservoir
When injection phase begins, the water-resaturation compaction is well predicted by the code. Additional deformations appear and are related to decrease of suction at the injection well.

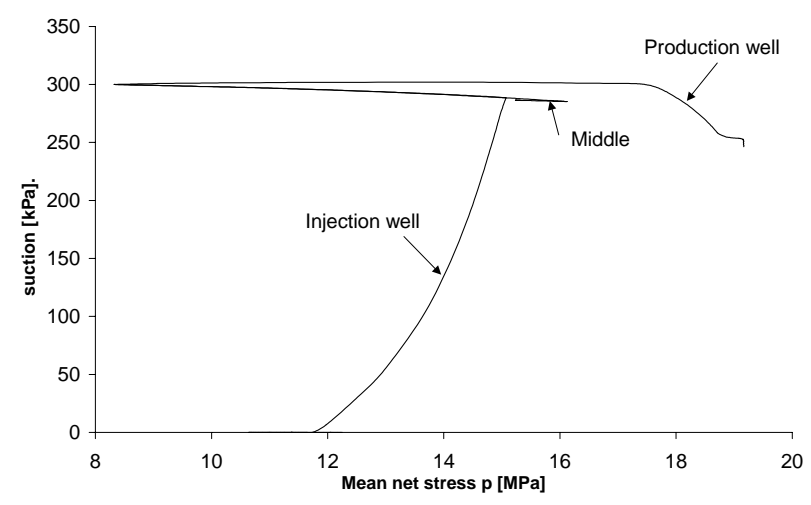

Figure 6. Stress path in the reservoir

Figure 6 presents stress paths (p-s plane) followed in finite elements located near the production well, the injection well and between them. During production phase, stress path in the three points is nearly horizontal: this means that suction does not vary a lot during production phase. When injection phase begins, one observes a brutal decrease of suction at the injection well. This leads to the additional compaction when the stress path reaches the LC curve. However, at the production well and at the midpoint, suction does not vary so much during the time scale considered in this simulation because the water front does not yet reach them.

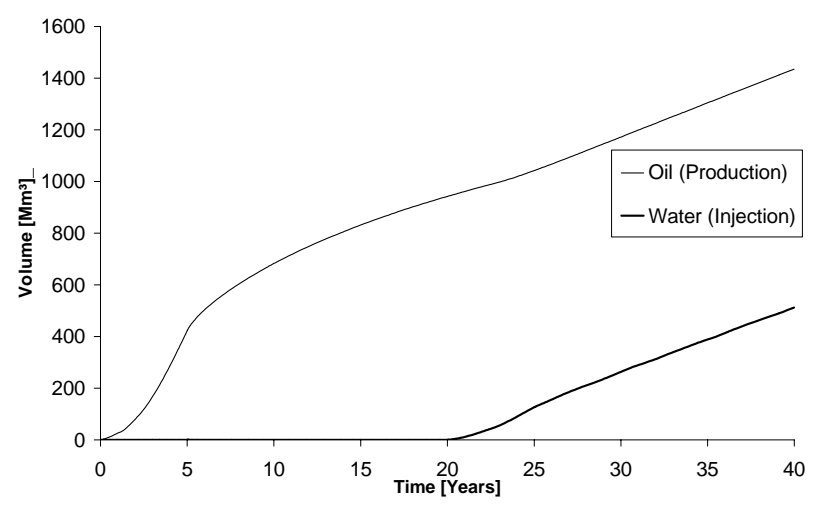

Figure 7. Oil production and water injection volumes

Oil production is clearly affected by the water injection (Figure 7). The oil production rate increases when the injection begins. Indeed the water flows out oil present in the reservoir. 
The results show that the constitutive relationship developed within Pasachalk project is able to reproduce the reservoir compaction related to water injection.

\section{CONCLUSIONS}

A multimechanism model is developed to describe the chalk behaviour during water flooding. The main assumption is that water sensitivity of chalk could be related to oil-water suction effects. The Barcelona model concepts are integrated into the PASACHALK constitutive law in order to reproduce suction dependency behaviour of chalk.

Experimental results obtained in the framework of Pasachalk project are used to define parameters. The validation of the constitutive law is achieved thanks to the modelling of water flooding experiment. Comparisons between experimental and numerical results show that our finite element code is able to reproduce the fluid mass transfer and the mechanical water sensitive behaviour of chalk.

This numerical tool may be used for simulations of oil reservoir chalk in order to reproduce the compaction during water injection. The computations presented here correspond to a hypothetical reservoir. The results show that the model is able to reproduce the compaction during production phase. These deformations are related to an increase of 'effective' stress. During injection phase, an additional compaction is predicted. Even if the reservoir pressure increases, the suction decrease leads to compressive deformations. Suction is a pertinent mechanism to explain the mechanical behaviour of chalk.

Another important aspect of chalk is its time dependent behaviour. We are currently developing an elasto-visco-plastic model including suction effects. This constitutive law will be able to deal with the main issues related to chalk.

\section{ACKNOWLEDGMENTS}

The authors are grateful to the EC-Joule programme, the FNRS and the Communauté Française de Belgique for their supports.

\section{REFERENCES}

Alonso, E.E. Gens, A. \& Josa, A. 1990. A constitutive model for partially saturated soils. Géotechnique 40(3): pp. 405-430.
Bear, J. 1972. Dynamics of fluids in porous media. American Elsevier Environmental science series 1972.

Collin, F. Li, X.L. Radu, J.P. \& Charlier, R. 2002a. Thermo-hydro-mechanical couplings in clay barriers. Engineering Geology (64): pp. 179193.

Collin, F. Cui, Y.J. Schroeder, C. \& Charlier, R. 2002b. Mechanical behaviour of Lixhe chalk partly saturated by oil and water: experiments and modelling. Int. Jl. Num. Anal. Meth. In Geom. (26): pp. 897-924.

Delage, P. Schroeder, C. \& Cui, Y.J. 1996. Subsidence and capillary effects in chalk. Proceedings Eurock 96, Turin 1996: pp. 1291 1298.

Homand S. 2000. Comportement mécanique d'une craie très poreuse avec prise en compte de l'effet de l'eau : de l'expérience à la simulation. Thèse de doctorat Université de Lille I.

Monjoie, A. Schroeder, C. Prignon, P. Yernaux, C. da Silva, F. \& Debande, G. 1990. Establishment of constitutive laws of chalk and long term tests. Proc. 3rd Sea Chalk Symposium, Copenhagen June 1990.

Schroeder, C. Bois, A.P. Maury, V. \& Hallé, G. 1998. Water/chalk (or collapsible soil) interaction: Part II. Results of tests performed in laboratory on Lixhe chalk to calibrate water/chalk models. SPE/ISRM Eurock'98 Trondheim (SPE 47587) 1998.

Schroeder C., Illing P., Charlier R., Collin F., Delage P., Cui Y.J., De Gennaro V., De Lebeek A., Keül P., Bois A.P. - EC PROJECT PASACHALK. Mechanical behaviour of partially and multiphase saturated chalks Fluidskeleton interaction : Main factor of chalk oil reservoirs compaction and related subsidence. Final report Contract $\mathrm{N}^{\circ} \mathrm{JOF} 3 \mathrm{CT} 970033$ of Non Nuclear Energy Programme JOULE III, 2000.

Simo, J.C. \& Hughes, T.J.R. 1998. Computational Inelasticity. Interdisciplinary applied mathematics, 7:198-218.

Teufel L.W. \& Farrel H.E. 1990. In situ stress and natural fracture distribution in the Ekofisk field, North Sea. Proc. Third North Sea Chalk Symposium, Copenhagen.

Van Eekelen, H.A.M. 1980. Isotropic yield surfaces in three dimensions for use in soil mechanics. International Journal for Numerical and Analytical Methods in Geomechanics 4:98101. 